\title{
Tolerância ao déficit hídrico: adaptação diferencial entre espécies forrageiras
}

\author{
Angelita Celente Martins' ${ }^{1}$, Cristina Ferreira Larré', Fernanda Bortolini' ${ }^{2}$, Junior Borella', \\ Rodrigo Eichholz', Dominique Delias' \& Luciano do Amarante'
}

\author{
'Universidade Federal de Pelotas, Instituto de Biologia, Departamento de Botânica, Universidade Campus s/n, CEP 96160-000, \\ Capão do Leão, Rio Grande do Sul, Brasil. angel-celente@hotmail.com \\ 2 Empresa Brasileira de Pesquisa Agropecuária, Estação Experimental Terras Baixas Clima Temperado, Capão do Leão, \\ Rio Grande do Sul, Brasil.
}

Recebido em 20.11.2016

Aceito em 27.VII.2018

DOI 10.21826/2446-8231201873302

RESUMO - O objetivo do trabalho foi caracterizar mecanismos de adaptação à restrição hídrica no solo em Macroptilium lathyroides (L.) Urb, Vigna luteola Jacq e Desmodium incanum DC, leguminosas com potencial forrageiro. Os tratamentos foram caracterizados pela suspensão da irrigação e manutenção das plantas em capacidade de campo, iniciados 60 dias após a semeadura. As avaliações foram realizadas aos quatro, 11 e 18 dias após a submissão ao déficit hídrico e aos dois, cinco e nove dias após a reidratação. $\mathrm{O}$ acúmulo de osmólitos, como acúcares solúveis e prolina, em folhas e raízes, constitui uma estratégia metabólica evidente para adaptação à restrição hídrica nas espécies estudadas, resultando numa menor interferência do estresse oxidativo em Desmodium incanum DC.

Palavras-chave: Desmodium, estresse, leguminosas, Macroptilium, Vigna

ABSTRACT - Tolerance to drought: adaptation differential between forage species. The aim of this study was to characterize adaptive mechanisms of forage potential plants (Macroptilium lathyroides L, Vigna luteola Jacq and Desmodium incanum DC) under water stress. The treatments were carried out by the suspension of irrigation and maintenance of the plants in field capacity, 60 days after sowing. The evaluations were performed at 4,11 , and 18 days after submission to the drought and with 2,5 and 9 days after rehydration. The osmolytes accumulation, soluble sugars and proline, constituted a clear strategy for metabolic adaptation to water stress in the studied species, resulting in less interference from the oxidative stress in Desmodium incanum DC.

Keywords: Desmodium, stress, legumes, Macroptilium, Vigna

\section{INTRODUÇÃO}

Algumas espécies nativas dos campos sul brasileiros podem apresentar elevado potencial de desempenho agronômico e aptidão para uso como forrageira na recuperação de pastagens degradadas para a utilização em sistemas pecuários sustentáveis. Destacando-se dentre estas espécies três leguminosas: Macroptilium lathyroides (L.) Urb, Desmodium incanum DC e Vigna luteola Jacq. Espécies que se desenvolvem em estações mais quentes e, assim estão sujeitas à alta incidência luminosa, altas temperaturas e baixa precipitação. Possuem características de adaptabilidade a diferentes ambientes e curto ciclo reprodutivo. Os períodos de estiagens limitam a sobrevivência de algumas espécies no Rio Grande do Sul, o que faz com que as mesmas, em alguns casos, alterem o metabolismo como forma de escapar ou tolerar a seca.

O efeito da deficiência hídrica sobre as plantas é complexo, e as mesmas respondem através de vários processos adaptativos, não havendo, para tanto, mecanismo universal de resistência à seca, mas certos tipos de adaptações dentro de cada grupo ecofisiológico, que as permitem resistirem à escassez de água (Nogueira et al. 2005). A resposta do vegetal ao déficit hídrico é amplamente influenciada pelo tempo, intensidade, duração e frequência do estresse, além das diversas interações planta-soloatmosfera e das condições climáticas (Saint Pierre et al. 2012, Driever \& Kromdijk 2013).

A redução do teor de água na planta, a diminuição do potencial hídrico foliar, a perda de turgor, fechamento dos estômatos e diminuição do crescimento celular constituem mecanismos de respostas de uma planta submetida ao estresse hídrico (Jaleel et al. 2009). O monitoramento do estresse hídrico é essencial para determinar o impacto no desenvolvimento e na produtividade das espécies. Porém, as respostas ao déficit hídrico podem variar de acordo com as diferentes fases de crescimento das plantas (Bürling et al. 2013). Sabe-se ainda que o estresse por déficit hídrico provoca alterações em diversas características fisiológicas, morfológicas e bioquímicas (Mishra et al. 2012).

Assim o presente trabalho teve por objetivo caracterizar algumas das alterações metabólicas que possam auxiliar no 
entendimento dos mecanismos fisiológicos e bioquímicos envolvidos na tolerância ao estresse por déficit hídrico em três espécies de leguminosas, Macroptilium lathyroides (L.) Urb, Desmodium incanum DC e Vigna luteola Jacq com potencial forrageiro, submetidas à restrição hídrica e posterior reidratação.

\section{MATERIAL E MÉTODOS}

O experimento foi desenvolvido no período de Janeiro a Abril de 2013 em casa de vegetação localizada no campus Capão do Leão da Universidade Federal de Pelotas (UFPel). Durante o período experimental, as médias das temperaturas mínima e máxima foram $25^{\circ}$ e $35^{\circ} \mathrm{C}$. Foram utilizadas plântulas obtidas a partir de sementes coletadas a campo, de leguminosas das espécies: M. lathyroides (L.) Urb (feijão do campo), V. luteola Jacq. (Feijão da praia), e $D$. incanum DC. (Pega-pega), cultivadas pela Embrapa Clima Temperado - Estação Experimental Terras Baixas, situada no município do Capão do Leão, RS.

As sementes foram semeadas em bandejas de polipropileno contendo substrato comercial (turfa fértil) e mantidas em condições de casa de vegetação, sob condições naturais de luz e temperatura. Após 49 dias de germinação e estabelecimento, as plântulas foram transplantadas para vasos plásticos perfurados, com capacidade de $3 \mathrm{~L}$, mantendo-se três plantas por vaso. $\mathrm{O}$ substrato utilizado foi constituído de turfa fértil e solo, na proporção de 1:1. A nutrição das plantas foi realizada por meio da aplicação de $150 \mathrm{~mL}$ de solução de Hoagland \& Arnon (1938) duas vezes por semana.

O tratamento com déficit hídrico foi iniciado 30 dias após o transplante através da suspensão da irrigação e o teor de umidade foi monitorado por gravimetria. As plantas do tratamento controle foram mantidas na capacidade de campo. A quantidade de água adicionada em cada vaso foi calculada com base na pesagem diária dos vasos em balança analítica. A superfície do vaso foi coberta com filme plástico durante a execução do experimento para evitar perdas de água por evaporação.

Após o período de 18 dias de déficit hídrico, as plantas destinadas a recuperação foram irrigadas de forma a manter $o$ solo na capacidade de campo. As avaliações foram realizadas aos quatro, 11 e 18 dias após a suspensão da irrigação (4dDH, 11d-DH e 18d-DH; DH= déficit hídrico) e aos dois, cinco e nove dias após a reidratação, considerado o período de recuperação (2d-R, 5d-R e 9d-R; R= reidratação). Em cada período de avaliação, foram coletadas amostras de folhas e raízes de 12 plantas por tratamento, perfazendo quatro repetições por tratamento, onde a unidade experimental consistiu em um vaso contendo três plantas. As amostras foram armazenadas em ultra-freezer a $-80^{\circ} \mathrm{C}$ para posteriores determinações bioquímicas.

\section{Dosagem de açúcares solúveis totais}

Os extratos, em raízes e folhas, foram obtidos conforme metodologia de Bieleski \& Turner (1966) com modificações. As amostras, cerca de $1 \mathrm{~g}$ de material vegetal, foram maceradas com $\mathrm{N}_{2}$ líquido e homogeneizadas com $10 \mathrm{~mL}$ de solução extratora MCW (metanol: clorofórmio: água; proporção de 12:5:3). Após $24 \mathrm{~h}$, os extratos foram centrifugados a $600 \mathrm{~g}$ por $30 \mathrm{~min}$. Para cada $4 \mathrm{~mL}$ de sobrenadante foi acrescentado $1,0 \mathrm{~mL}$ de clorofórmio e 1,5 $\mathrm{mL}$ de água e centrifugado novamente para a separação de fases. O sobrenadante contendo os metabólitos foi coletado e transferido para banho-maria a $38^{\circ} \mathrm{C}$, permanecendo por cerca de 30 h para eliminação do resíduo de clorofórmio e concentração das amostras para as análises de açúcares.

A quantificação de açúcares solúveis totais (AST) foi realizada com base em Graham \& Smydzuk (1965). Coletou-se $1,0 \mathrm{~mL}$ de cada amostra, do branco (água) e dos padrões (10-150 $\mu \mathrm{g}$ de glicose $\left.\mathrm{mL}^{-1}\right)$, em tubos de ensaio, mantidos em gelo. Adicionou-se $3 \mathrm{~mL}$ de solução de antrona $(0,15 \% \mathrm{p} / \mathrm{v}$ em ácido sulfúrico concentrado) resfriada a cada tubo e cobriu-se imediatamente com bolinhas de vidro. Após $15 \mathrm{~min}$, agitaram-se os tubos e incubou-se em banho-maria a $90^{\circ} \mathrm{C}$ por $20 \mathrm{~min}$. Em seguida, mantiveramse os tubos no escuro até a atingir temperatura ambiente. Os tubos foram novamente agitados e a densidade óptica (D.O.) dos padrões, foram medidas em espectrofotômetro a $620 \mathrm{~nm}$ (marca Biospectro, modelo SP-22).

\section{Quantificação de prolina}

Determinada de acordo com Bezerra Neto \& Barreto (2011). Amostras com 0,25g de folhas e raízes frescas foram trituradas em $\mathrm{N}_{2}$ líquido, seguida da adição de 2 $\mathrm{mL}$ de ácido sulfossalicílico a 3\% em homogeneizador. $\mathrm{O}$ extrato obtido foi centrifugado por 10 minutos a $1.000 \mathrm{~g}$. Após a centrifugação, em cada tubo de ensaio rosqueável foi adicionado $1,0 \mathrm{~mL}$ do sobrenadante; $2,0 \mathrm{~mL}$ de ninhidrina ácida contendo $1,25 \mathrm{~g}$ de ninhidrina com (30 $\mathrm{mL}$ de ácido acético glacial e $20 \mathrm{~mL}$ de ácido fosfórico $6 \mathrm{M}$ em agitador); 2,0 $\mathrm{mL}$ de ácido acético glacial e 2,0 mL de água destilada. Os tubos levados ao banho-maria, por uma hora a $100^{\circ} \mathrm{C}$ e, posteriormente, transferidos para banho de gelo. Após esse procedimento, foram acrescentados $4,0 \mathrm{~mL}$ de tolueno e agitados vigorosamente, por 20 segundos, para a separação das fases. O sobrenadante foi aspirado da fase aquosa, para ser feita a leitura em espectrofotômetro no comprimento de onda de $520 \mathrm{~nm}$. A concentração de prolina foi determinada usando-se a curva padrão, preparada com concentrações conhecidas de prolina: $0 ; 0,10 ; 0,25 ; 0,50 ; 1,1,50$ e $2 \mathrm{mg} \mathrm{L}^{-1}$.

\section{Extravasamento de eletrólitos (EE)}

Foram coletados dez discos foliares, com aproximadamente $0,5 \mathrm{~cm}$ cada e dez segmentos de raízes. As amostras foram lavadas em água destilada e secas em papel absorvente e, posteriormente, colocadas em frascos contendo $10 \mathrm{~mL}$ de água pura a $25^{\circ} \mathrm{C}$ por 24 horas. Após este período, a condutividade elétrica do meio, onde estavam embebidas as amostras, foi medida (C1) e os frascos com os discos foliares e os segmentos de raízes foram colocados em banho-maria a $90^{\circ} \mathrm{C}$ por $2 \mathrm{~h}$. Após 
atingirem a temperatura ambiente a condutividade elétrica máxima foi medida $(\mathrm{C} 2)$ e o extravasamento de eletrólitos calculado através da fórmula e expresso em porcentagem: $\mathrm{E}=(\mathrm{C} 1 / \mathrm{C} 2) \times 100$, de acordo com Bajji et al. (2002).

\section{Quantificação de peróxido de hidrogênio e peroxidação lipídica}

$\mathrm{O}$ conteúdo de peróxido de hidrogênio $\left(\mathrm{H}_{2} \mathrm{O}_{2}\right)$ foi determinado em folhas e raízes, conforme metodologia descrita por Velikova et al. (2000). O material vegetal, 200 mg por amostra, foi macerado em $2 \mathrm{~mL}$ de uma solução a $0,1 \%(\mathrm{w} / \mathrm{v})$ de ácido tricloacético (TCA) e o homogeneizado foi centrifugado a $10.000 \mathrm{~g}$ por $10 \mathrm{~min}$ a $4^{\circ} \mathrm{C}$. A seguir, $300 \mu \mathrm{L}$ da amostra foram adicionados a $700 \mu \mathrm{L}$ de tampão fosfato de potássio $10 \mathrm{mM}(\mathrm{pH} 7.0)$ e $1 \mathrm{~mL}$ de iodeto de potássio $1 \mathrm{M}$. As leituras de absorbância a 390nm foram registradas utilizando espectrofotômetro marca Biospectro, modelo SP-22 e a concentração de $\mathrm{H}_{2} \mathrm{O}_{2}$ expressa em $\mu \mathrm{mol}$ de $\mathrm{H}_{2} \mathrm{O}_{2} \mathrm{~g}^{-1}$ de massa fresca, com base em uma curva padrão de $\mathrm{H}_{2} \mathrm{O}_{2}$ em concentrações variando de $0,10,20$, 30,40 e $50 \mu \mathrm{mol}$.

A peroxidação de lipídios foi determinada por medodologia descrita por Cakmac \& Horst (1991), através da medição da concentração de espécies reativas ao ácido tiobarbitúrico (TBARS). Amostras de $200 \mathrm{mg}$ de folhas e raízes foram maceradas em $\mathrm{N}_{2}$ líquido acrescido de $20 \%$ de PVPP (Polivinilpolipirrolidona) e homogeneizadas em ácido tricloroacético (TCA) $0,1 \%(\mathrm{p} / \mathrm{v})$. O homogeneizado foi centrifugado a $10.000 \mathrm{~g}$ por 10 minutos. A seguir, 250 $\mu \mathrm{L}$ do sobrenadante foram adicionados a $1 \mathrm{~mL}$ da solução contendo $0,5 \%(\mathrm{p} / \mathrm{v})$ de ácido tiobarbitúrico (TBA) e $10 \%$ $(\mathrm{p} / \mathrm{v})$ de TCA. O meio de reação foi incubado a $95^{\circ} \mathrm{C}$ por 30 minutos mantendo os tubos fechados, paralisando a reação por resfriamento rápido em banho de gelo. A absorbância das TBARS formadas foi determinada em espectrofotômetro a $535 \mathrm{~nm}$ e $600 \mathrm{~nm}$. O TBA forma complexos de cor avermelhada com aldeídos de baixa massa molecular, como o malondialdeído (MDA), produto secundário do processo de peroxidação. A concentração do complexo MDA/TBA foi calculada pela seguinte equação: $[\mathrm{MDA}]=\left(\mathrm{A}_{535}-\mathrm{A}_{600}\right) /(\xi . \mathrm{b})$, onde: $\xi$ (coeficiente de extinção $=1,56 \times 10^{-5} \mathrm{~mol}^{-1} \mathrm{~cm}^{-1}$ ) e b: (comprimento ótico $=1)$. A peroxidação foi expressa em nmol de MDA $\mathrm{g}^{-1}$ de matéria fresca.

O delineamento experimental utilizado foi em blocos ao acaso, com quatro repetições, sendo a unidade experimental representada por um vaso contendo três plantas. Os dados foram submetidos a análise de variância (ANOVA) e as médias comparadas pelo Teste de Tukey $(p \leq 0,05)$ através do programa Winstat (Machado \& Conceição 2007).

\section{RESULTADOS}

Os resultados obtidos pela quantificação dos teores de açúcares solúveis totais (AST) na parte aérea e raízes de $M$. lathyroides estão apresentados na Figura 1. Na parte aérea não foi observada diferença estatística entre períodos ou entre tratamentos (Fig. 1A). No entanto, a avaliação na raiz evidenciou diferença significativa entre períodos e tratamentos (Fig. 1B). Os níveis de AST mais elevados foram observados aos 18d-DH, sendo os mesmos reduzidos após a reidratação, chegando ao final do experimento, com níveis iguais aos das plantas controle.

Em D. incanum, os teores de açúcares solúveis totais na parte aérea apresentaram diferença significativa entre períodos e tratamentos (Fig. 1C). Os resultados obtidos para esta variável demonstraram um aumento nos teores de AST, aos 11d-DH e 18d-DH, retomando a valores próximos aos encontrados nas plantas do tratamento controle a partir de 2d-R. Nas raízes, os teores de AST foram reduzidos, comparados aos das plantas controle, desde o início do período experimental (4d-DH) até o final do período de restrição hídrica (18d-DH), sendo os mesmos aumentados aos níveis do controle a partir do primeiro período de recuperação (2d-R) até o final do experimento (Fig. 1D).

Os resultados obtidos em $V$. luteola não apresentaram diferença significativa entre os tratamentos quando foram avaliados na parte aérea (Fig. 1E). Os resultados foram significativos apenas quando comparados os períodos. No entanto, nas raízes foi evidenciada diferença significativa entre os tratamentos, sendo que os níveis mais acentuados foram observados aos $18 \mathrm{~d}-\mathrm{DH}$, retomando à níveis próximos do tratamento controle após a reidratação (Fig. 1F).

Os resultados obtidos na quantificação de prolina em $M$. lathyroides apresentaram diferença significativa entre períodos e tratamentos, tanto na parte aérea como na raiz (Figs. 2A e 2B, respectivamente). Nos tecidos foliares os teores de prolina, em plantas sob restrição hídrica, foram incrementados aos 11d-DH com aumento crescente até os $2 \mathrm{~d}-\mathrm{R}$, sendo os mesmos reduzidos ao final do período experimental, com valores equivalentes aos do controle (Fig. 2A).

Nas raízes das plantas de $M$. lathyroides sob deficiência hídrica, os teores de prolina, foram superiores aos das plantas do controle, aos $11 \mathrm{~d}-\mathrm{DH}$ até 5d-R, evidenciando-se os níveis mais altos de prolina nas raízes aos 18d-DH. No último período avaliado ( $9 \mathrm{~d}-\mathrm{R})$ os valores observados não diferiram das plantas controle (Fig. 2B).

Os teores de prolina na parte aérea de D. incanum, aumentaram aos 11d-DH e aos 18d-DH, na condição de déficit hídrico, diferindo significativamente em relação ao controle e período de tratamento, restabelecendo-se aos 2d-R (Fig. 2C). Nas raízes, foi observada diferença significativa, com o maior incremento nos níveis de prolina aos 11d-DH, mantendo-se superior ao controle aos 18d-DH e $2 \mathrm{~d}-\mathrm{R}$, igualando-se aos níveis das plantas controle nos períodos subsequentes (Fig. 2D).

Em $V$. luteola, foi evidenciado incremento nos níveis de prolina, nas plantas submetidas à restrição hídrica, desde o primeiro período avaliado, tanto em tecidos foliares (Fig. 2E) como nas raízes (Fig. 2F). Nas raízes, no entanto, houve redução nos níveis de prolina igualando-se aos níveis do controle no último período avaliado ( $9 \mathrm{~d}-\mathrm{R})$, o que não foi observado nos tecidos aéreos. 
Macroptilium lathyroides

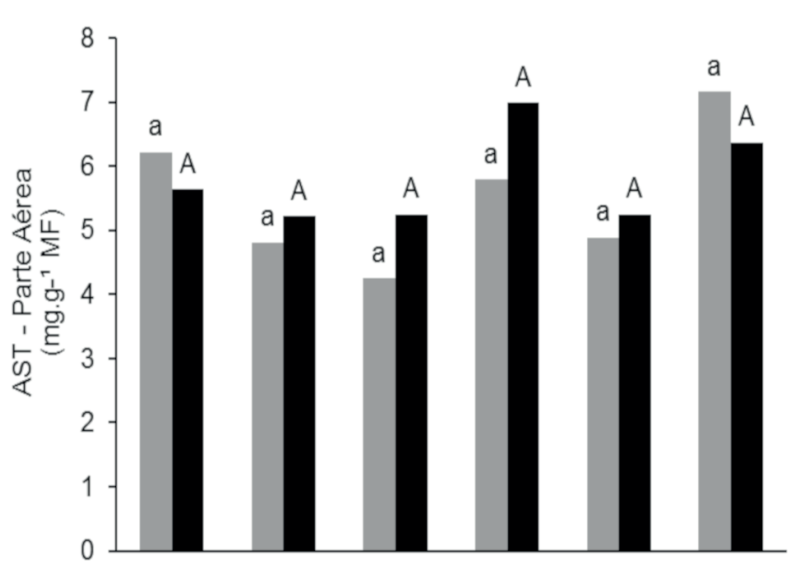

Desmodium incanum

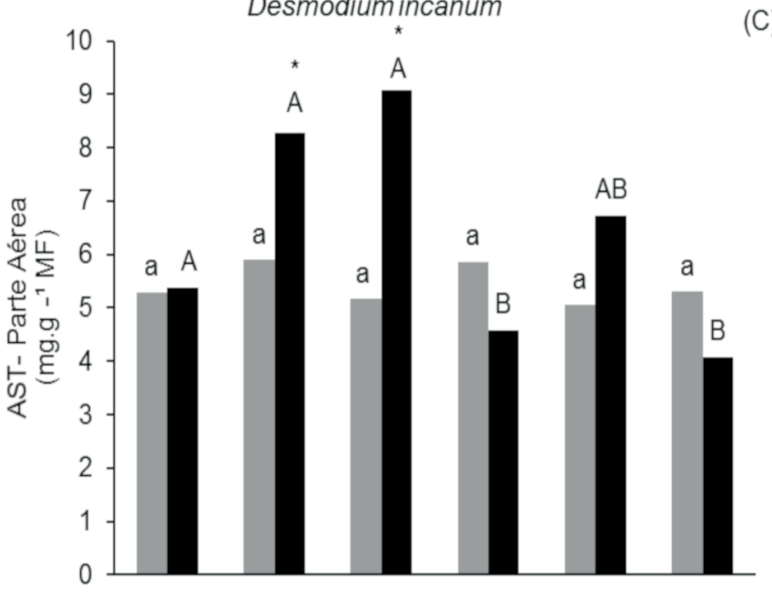

Vigna luteola

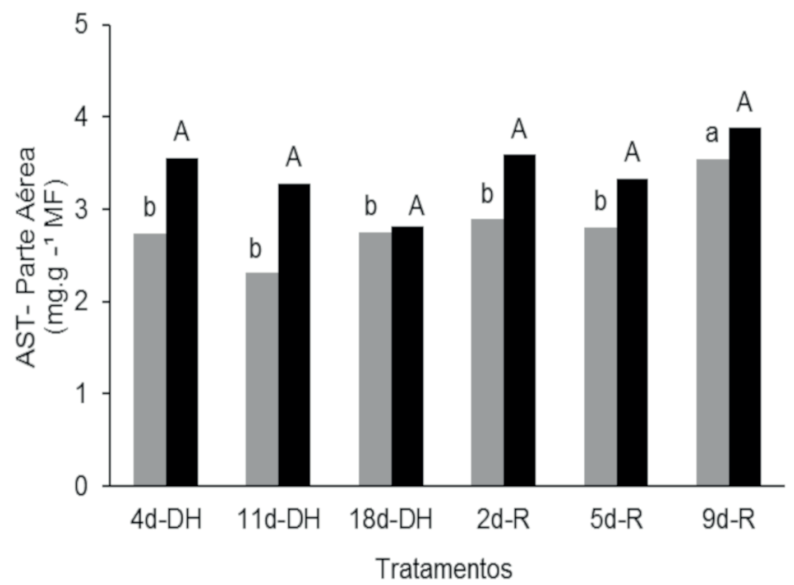

C)

(E)
Macroptilium lathyroides

(B)
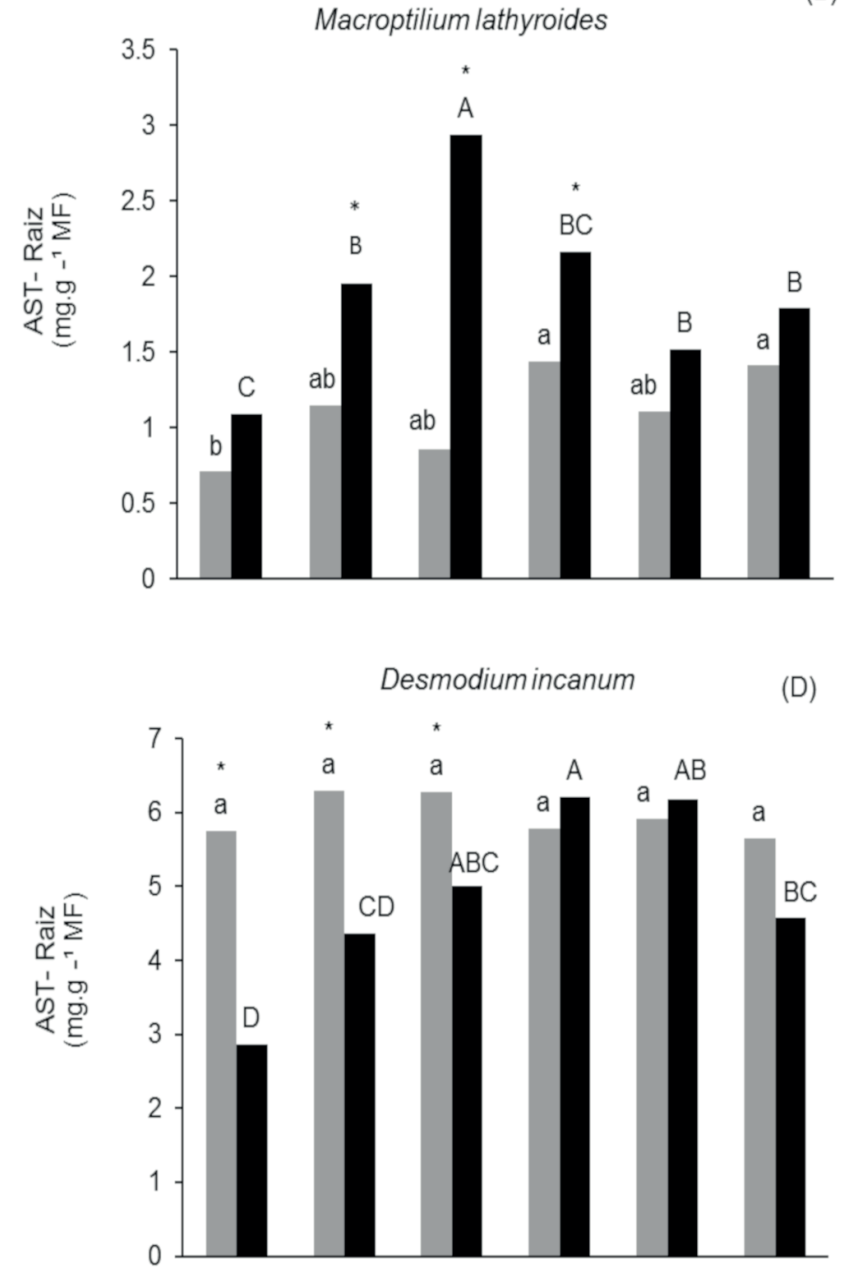

Vigna luteola

(F)



Figs. 1A-F. Teores de açúcares solúveis totais (AST) na parte aérea (A, C, E) e raízes (B, D, F) de M. lathyroides, D. incanum e V. luteola submetidas a diferentes períodos de déficit hídrico (4d-DH; 11d-DH; 18d-DH) e posterior reidratação (2d-R; 5d-R; 9d-R). Letras minúsculas comparam períodos para o controle e letras maiúsculas comparam períodos para déficit hídrico $\mathrm{DH}$ e reidratação, R. Asteriscos comparam regime hídrico: controle e déficit hídrico $\mathrm{DH}$ ou reidratação, $\mathrm{R}$. Letras iguais não diferem entre si pelo teste de Tukey $5 \%$ de probabilidade.

Os resultados obtidos na avaliação do extravasamento de eletrólitos nas folhas de $M$. lathyroides demonstraram aumento nessa variável, quando considerado os períodos de avaliação, tanto nas plantas controle quanto nas submetidas ao déficit hídrico (Fig. 3A). No entanto, aos 11d-DH e aos $18 \mathrm{~d}-\mathrm{DH}$, foi observado aumento mais drástico 

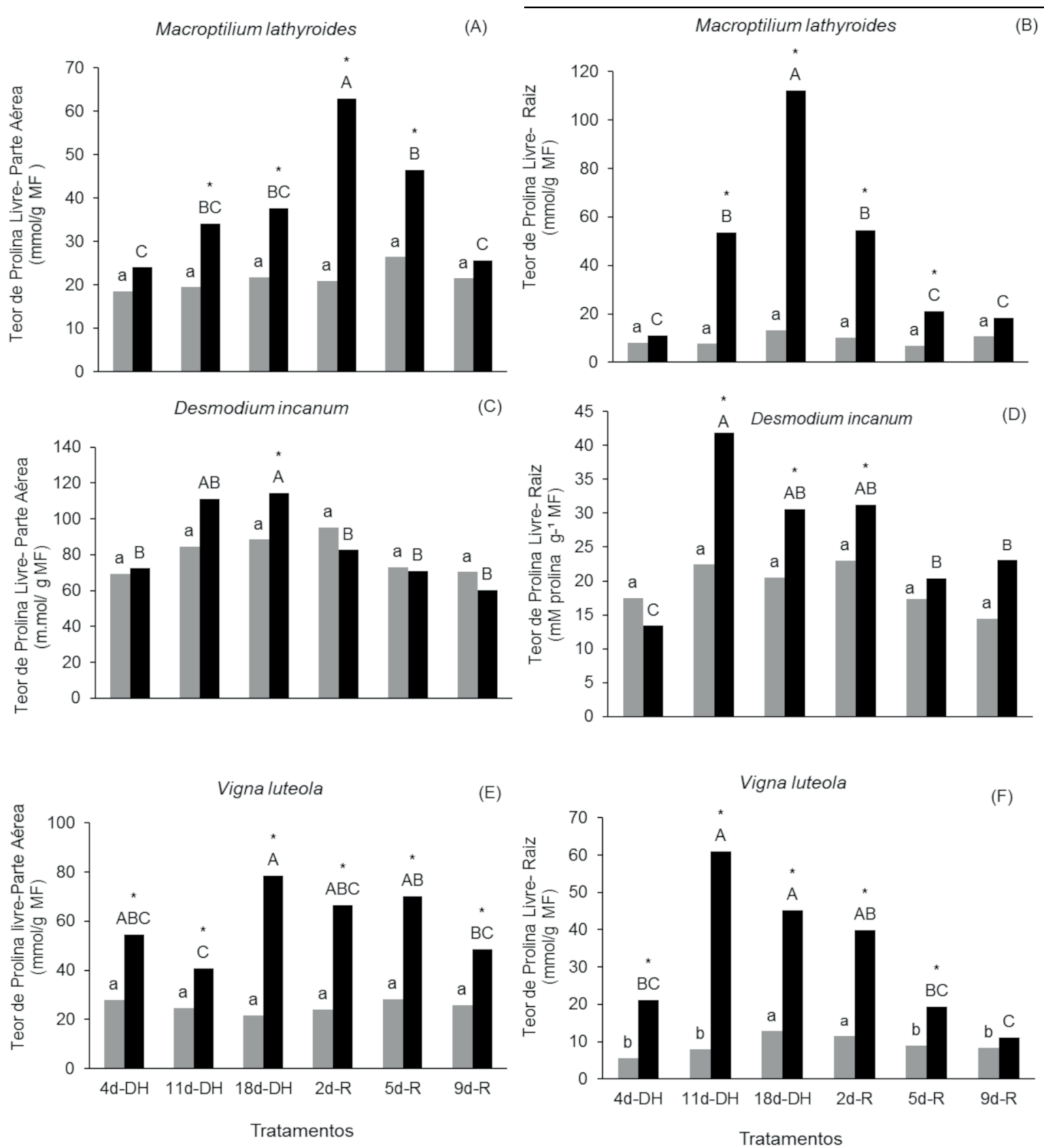

Figs. 2A-F. Teores de prolina livre na parte aérea (A, C, E) e raízes (B, D, F) de M. lathyroides, D. incanum e V. luteola submetidas a diferentes períodos de déficit hídrico (4d-DH; 11d-DH; 18d-DH) e posterior reidratação (2d-R; 5d-R. 9d-R). Letras minúsculas comparam períodos para o controle e letras maiúsculas comparam períodos para déficit hídrico $\mathrm{DH}$ e reidratação, R. Asteriscos comparam regime hídrico: controle e déficit hídrico DH ou reidratação, R. Letras iguais não diferem entre si pelo teste de Tukey 5\% de probabilidade.

desses valores nas plantas sob restrição hídrica, diferindo significativamente das plantas do tratamento controle.

Nas raízes, os resultados obtidos para o extravasamento de eletrólitos mostraram diferença significativa entre os tratamentos a partir de 4d-DH mantendo-se até aos 18d$\mathrm{DH}$, período onde foram observados os maiores valores para esta variável (Fig. 3B).

Após a reidratação (2d-R) houve restabelecimento desses valores igualando-se ao controle até o final do período experimental.
Em plantas de $D$. incanum, na parte aérea não foram observadas diferença significativa entre os tratamentos, apenas entre períodos (Fig. 3C). Nos dois regimes hídricos houve incremento dessa variável ao longo do período experimental. No entanto, nas raízes os resultados demonstraram diferença entre períodos e tratamentos, mostrando interação entre os fatores. Os maiores valores foram observados aos 18d-DH, diferindo das plantas controle até $5 \mathrm{~d}-\mathrm{R}$, após esse período os valores foram restabelecidos aos níveis das plantas controle (Fig. 3D). 
Na Figura 3 estão apresentados os resultados do extravasamento de eletrólitos em folhas (3E) e raízes (3F) de $V$. luteola. Em folhas os resultados evidenciaram diferença significativa entre períodos e regime hídrico. As plantas submetidas ao déficit hídrico apresentaram valores superiores aos 18d-DH; 2d-R e aos 5d-R, diferindo, nesses períodos, das plantas do tratamento controle.

Nas raízes os resultados obtidos apresentaram diferença significativa entre períodos e tratamentos, com interação entre os dois fatores. Os níveis de extravasamento nas
Macroptilium lathyroides

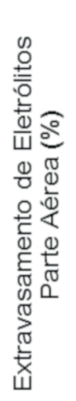

(A)

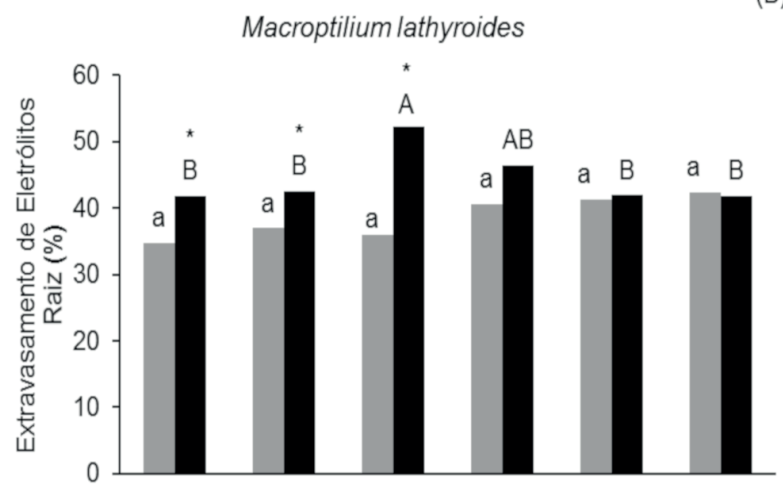

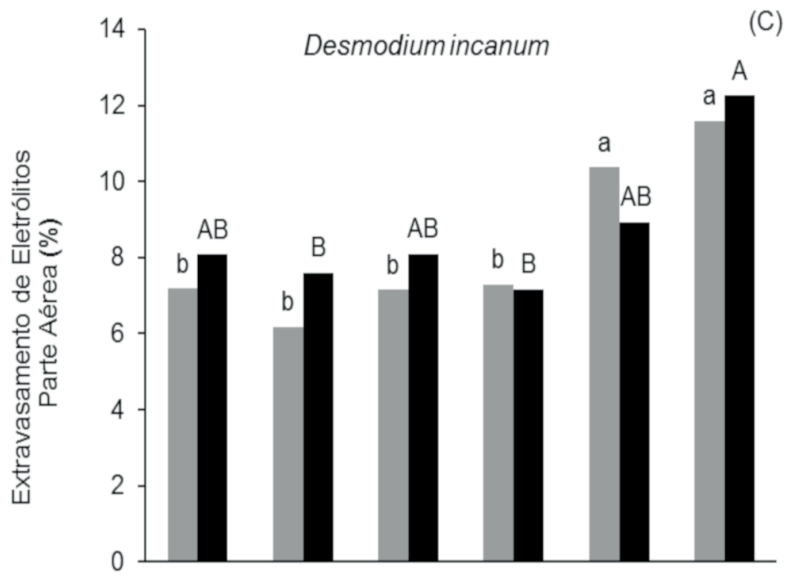

Vigna luteola

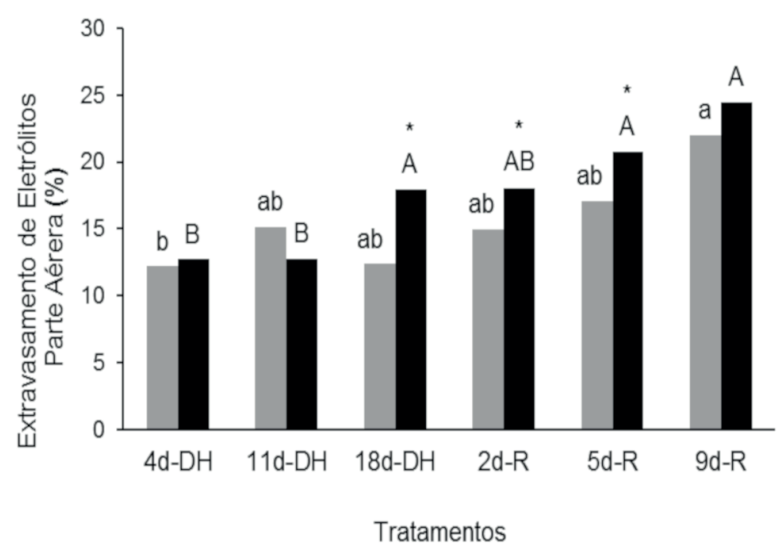

)
(C)



(D)

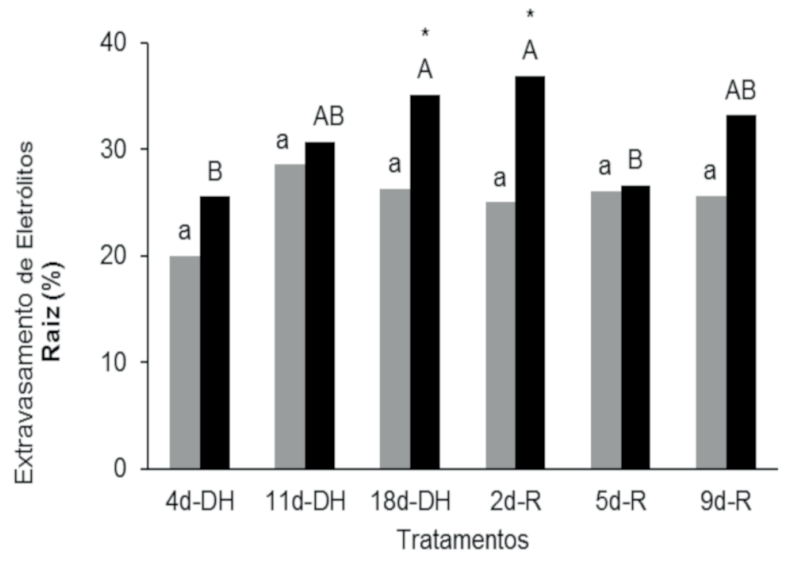

Figs. 3A-F. Extravasamento de eletrólitos na parte aérea (A, C, E) e raízes (B, D, F) de M. lathyroides, D. incanum e V. luteola submetidas a diferentes períodos de déficit hídrico (4d-DH; 11d-DH; 18d-DH) e posterior reidratação (2d-R; 5d-R; 9d-R). Letras minúsculas comparam períodos para o controle e letras maiúsculas comparam períodos para déficit hídrico DH e reidratação, R. Asteriscos comparam regime hídrico: controle e déficit hídrico DH ou reidratação, R. Letras iguais não diferem entre si pelo teste de Tukey $5 \%$ de probabilidade. 
raízes nas plantas sob restrição hídrica também foram superiores aos obtidos nas plantas controle, sobretudo aos 18d-DH e aos 2d-R.

Em relação aos teores de malondialdeído (MDA) nos tecidos foliares de Macroptilium, não foi observada diferença significativa entre os tratamentos ou períodos (Fig. 4A). Nas raízes, os níveis de MDA em plantas submetidas ao déficit hídrico, foram superiores aos $2 \mathrm{~d}-\mathrm{R}$ e aos $5 \mathrm{~d}-\mathrm{R}$, quando comparados aos das plantas controle (Fig. 4B), apresentando diferença significativa entre períodos.

Macroptilium lahyroides

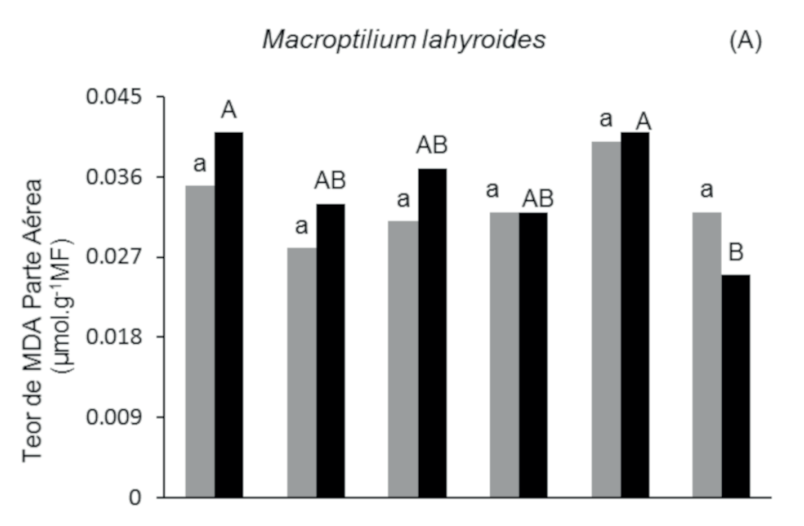

Os resultados obtidos em $D$. incanum, não mostraram diferença significativa nos tecidos foliares (Fig. 4C). No entanto, nas raízes os níveis de MDA diferiram entre os tratamentos e períodos. Foi observado, nas plantas tratadas sob restrição hídrica, aumento nos níveis de MDA aos 11d$\mathrm{DH}$ e aos 18d-DH, retomando, nos períodos posteriores, a níveis próximos aos observados nas plantas controle (Fig. 4D).

Os teores de MDA em plantas de V. luteola apresentaram diferença significativa para regime hídrico e período, tanto nos tecidos foliares como nas raízes (Figs. 4E e $4 \mathrm{~F}$ ).
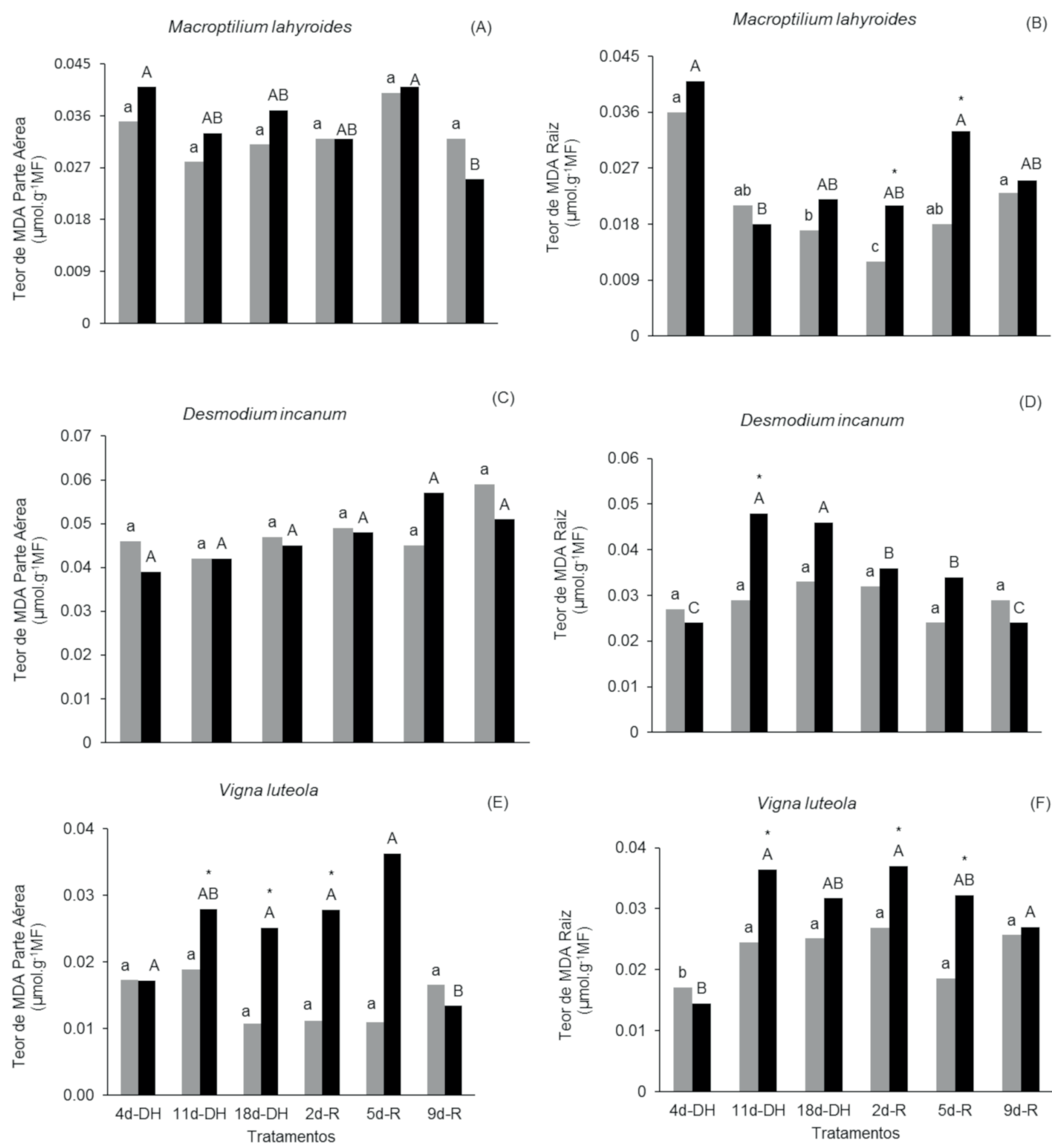

(E)



Figs. 4A-F. Teores de malondialdeído (MDA) na parte aérea (A, C, E) e raízes (B, D, F) de M. lathyroides, D. incanum e V. luteola submetidas a diferentes períodos de déficit hídrico (4d-DH; 11d-DH; 18d-DH) e posterior reidratação (2d-R; 5d-R; 9d-R). Letras minúsculas comparam períodos para o controle e letras maiúsculas comparam períodos para déficit hídrico $\mathrm{DH}$ e reidratação, $\mathrm{R}$. Asteriscos comparam regime hídrico: controle e déficit hídrico DH ou reidratação, R. Letras iguais não diferem entre si pelo teste de Tukey $5 \%$ de probabilidade. 
Houve um incremento nos níveis de MDA, nos dois órgãos, aos $11 \mathrm{~d}-\mathrm{DH}$ até os $5 \mathrm{~d}-\mathrm{R}$., porém, ao final do período experimental os níveis de MDA nas plantas submetidas ao déficit hídrico se igualaram às das plantas controle, tanto na parte aérea como nas raízes.

Macroptilium lathyroides

(A)

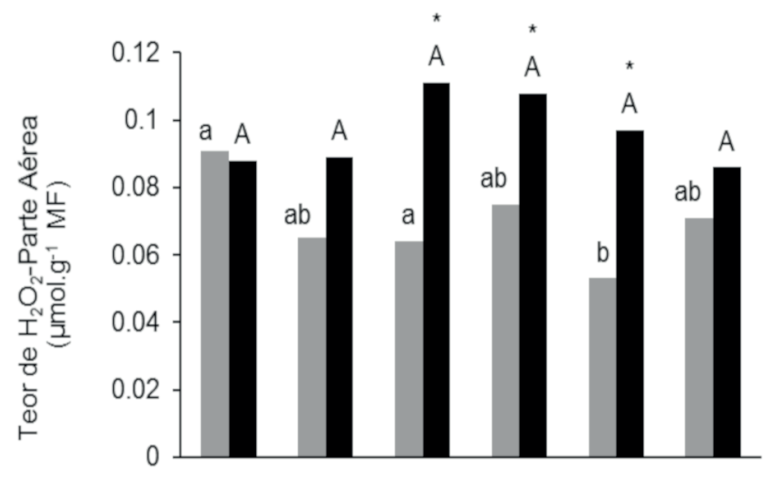

Desmodiumincanum

(C)

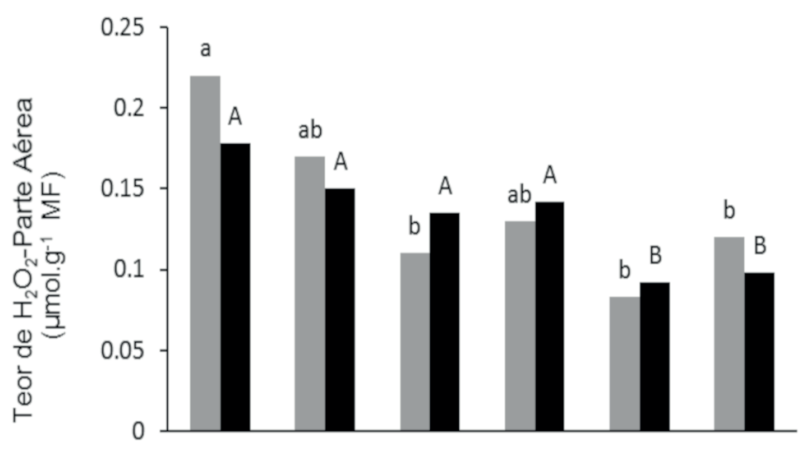

(E)

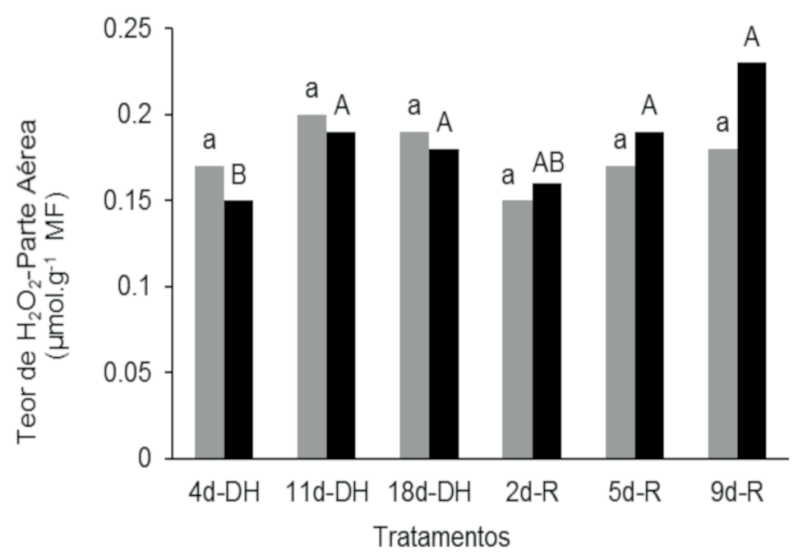

Os resultados obtidos na quantificação de peróxido de hidrogênio $\left(\mathrm{H}_{2} \mathrm{O}_{2}\right)$ em plantas de $M$. lathyroides mostraram diferença significativa entre períodos e regime hídrico, tanto na parte aérea como nas raízes (Figs. 5A e 5B). Os maiores níveis de $\mathrm{H}_{2} \mathrm{O}_{2}$ nas folhas, das plantas submetidas

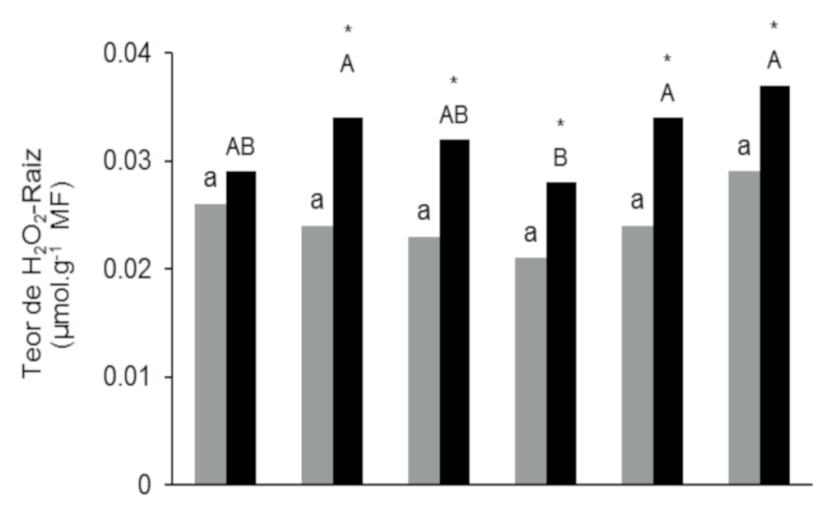

Desmodium incanum

(D)

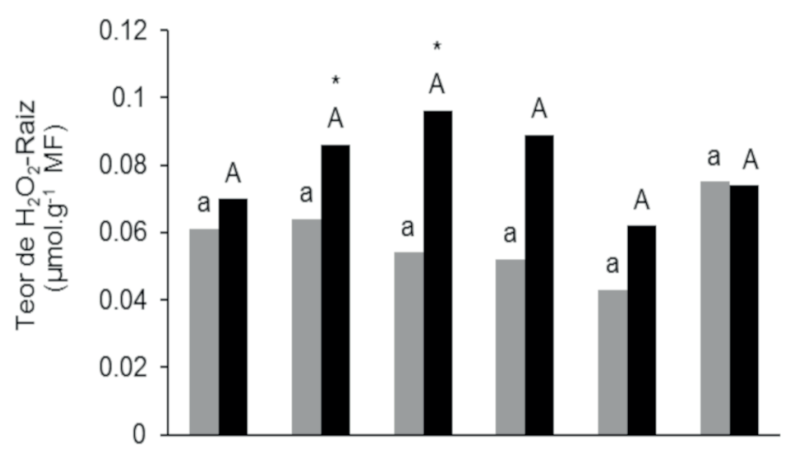

Vigna luteola

(F)

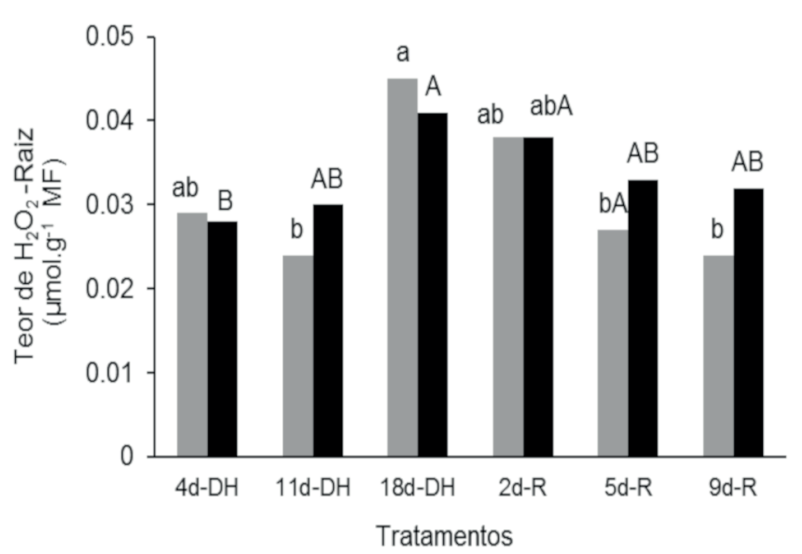

Figs. 5A-F. Teores de $\mathrm{H}_{2} \mathrm{O}_{2}$ na parte aérea (A, C, E) e raízes (B, D, F) de $M$. lathyroides, D. incanum e $V$. luteola submetidas a diferentes períodos de déficit hídrico (4d-DH; 11d-DH; 18d-DH) e posterior reidratação (2d-R; 5d-R; 9d-R). Letras minúsculas comparam períodos para o controle e letras maiúsculas comparam períodos para déficit hídrico $\mathrm{DH}$ e reidratação, R. Asteriscos comparam regime hídrico: controle e déficit hídrico DH ou reidratação, R. Letras iguais não diferem entre si pelo teste de Tukey $5 \%$ de probabilidade. 
ao déficit hídrico, foram observados aos 18d-DH, mantendo superiores aos das plantas controle até $5 \mathrm{~d}-\mathrm{R}$, e igualandose apenas no último período avaliado (9d-R) (Figs. 5A).

Nas raízes, as plantas sob restrição hídrica apresentaram acréscimo nos níveis de $\mathrm{H}_{2} \mathrm{O}_{2}$ a partir dos $11 \mathrm{~d}-\mathrm{DH}$ não restabelecendo valores equivalentes aos do controle até o final do período experimental (Fig. 5B).

Na Figura 5 (C e D) estão apresentados os resultados da quantificação de $\mathrm{H}_{2} \mathrm{O}_{2}$ em plantas de D. incanum. Nas folhas não foi observada diferença significativa entre os tratamentos, apenas entre períodos, evidenciado maiores teores de $\mathrm{H}_{2} \mathrm{O}_{2}$ aos 4d-DH, nos dois regimes hídricos (Fig. 5C). No entanto, nas raízes, foi evidenciada diferença significativa entre períodos e tratamentos (Fig. 5D). Aos 11d-DH, 18d-DH e 2d-R foram observados os maiores níveis de $\mathrm{H}_{2} \mathrm{O}_{2}$ nas plantas submetidas à restrição hídrica quando comparadas aos níveis das plantas controle. Ao final do período experimental esses valores se igualaram.

Os níveis de peróxido de hidrogênio nas folhas de plantas de $V$. luteola submetidas ao déficit hídrico não apresentaram diferenças significativas entre os tratamentos quando comparadas ao nível nas plantas controle (Fig. 5E). Nas raízes, os níveis de $\mathrm{H}_{2} \mathrm{O}_{2}$ também não diferiram das plantas controle, quanto ao regime hídrico. Porém, quando comparados os períodos foi observado um incremento nos valores de $\mathrm{H}_{2} \mathrm{O}_{2}$, nos dois regimes hídricos, aos 18d-DH, com pequena redução após esse período.

\section{DISCUSSÃO}

O estresse hídrico desencadeia um conjunto de respostas fisiológicas, bioquímicas e moleculares nas plantas, que desenvolvem mecanismos de adaptação às circunstâncias ambientais limitantes, variando de acordo com a intensidade, com o tempo de estresse, com a interação, com outros tipos de estresse, com o estádio de desenvolvimento e o genótipo (Meneses et al. 2006).

A maioria dessas modificações visa manter o crescimento e a reprodução da planta em ambientes com limitações na disponibilidade de água. Uma das mais bem documentadas respostas fisiológicas ao déficit hídrico em plantas é a habilidade de algumas espécies de ajustar osmoticamente suas células. Durante a seca, plantas superiores acumulam açúcares, ácidos orgânicos e íons no citosol para diminuir o potencial osmótico e, consequentemente, manter o potencial hídrico e o turgor de suas células próximo do nível ótimo (Maia et al. 2007).

Em algumas plantas, que apresentam fortes reduções na condutância estomática e na transpiração quando expostas ao déficit hídrico, a ascensão de seiva via xilema pode ser favorecida pela síntese ou pelo acúmulo de solutos (orgânicos e inorgânicos) osmoticamente ativos no citosol (Nepomuceno et al. 2001). O acúmulo desses compostos nas folhas reduz o potencial hídrico foliar $\left(\Psi_{\mathrm{w}}\right)$, o que aumenta a capacidade de absorção de água das plantas e até amenizando os efeitos do déficit hídrico no conteúdo relativo de água da planta (Pagter et al. 2005).
As espécies estudadas apresentaram respostas diferenciadas quanto aos teores de açúcares solúveis totais (AST) e quanto ao órgão preferencial de síntese e/ ou acúmulo destes. M. lathyroides (Fig. 1B) apresentou aumento nos teores de açúcares solúveis totais a partir dos 11d-DH, mantendo-se superior até o início do período de recuperação (2d-R) e V. luteola (Fig. 1F), apenas aos 18dDH. Enquanto D. incanum reduziu os teores de AST em raízes a partir dos $4 \mathrm{~d}-\mathrm{DH}$ e, em contrapartida, aumentaram esses níveis na parte aérea ao 11 e 18 d-DH (Figs. 1C e 1D). Sugerindo que em Macroptilium e Vigna a resposta à imposição do estresse hídrico ocorre nas raízes, órgão diretamente afetado pela restrição hídrica. No entanto, as três espécies, após a reidratação reduzem a concentração de AST ao mesmo nível das plantas controle, independente do órgão onde o mesmo foi acumulado.

Maia et al. (2007) estudando cultivares de milho, submetidos a estresse hídrico, verificou a elevação da concentração de AST nas folhas a partir de cinco dias, aumentando significativamente. Resultados semelhantes foram encontrados em plantas de Gossypium hirsutum L. (Marur 1998), em Medicago sativa (Chaves Filho \& Stacciarini-Seraphin, E. 2001) e em Schizolobium parahyba (Vell.) S.F. Blake (Weidlich \& Pescador 2010), sob condições de estresse hídrico, que apresentaram níveis de açúcares aumentados, assemelhando-se aos resultados obtidos na parte aérea da espécie $D$. incanum.

Aumentos significativos nos teores de açúcares solúveis em raízes também foram encontrados por Souza et al. (2004) e Oliveira-Neto et al. (2006) em experimentos realizados com as cultivares de Vigna unguiculata Vita-7 e Sempre Verde, respectivamente. Após reidratação, as plantas que sofreram deficiência hídrica, apresentaram teores de açúcares solúveis semelhantes ao controle, corroborando com os mesmos resultados encontrados com $M$. lathyroides e $V$. luteola, que apresentaram, níveis altos de AST aos 18d-DH (Figs. 1B, 2F), retomando seus níveis quando reidratadas. Esse acúmulo serve de reserva de carbono para a imediata retomada de crescimento, assim que ocorre o balanço hídrico apropriado.

Acúmulos de prolina foram encontrados em feijão Vigna submetidos a estresse hídrico, sendo esse osmólito considerado um marcador bioquímico do estresse hídrico para os genótipos de ciclo intermediário, diferenciando-os dos genótipos de ciclo tardio (Santos et al. 2010).

Neste trabalho também foram observados aumentos expressivos nos teores de prolina nas três espécies estudadas, tanto nos tecidos foliares como nos radiculares (Fig. 2). Da mesma forma como foi observado em diversas espécies submetidas ao déficit hídrico, como em feijãomungo (Hamidou et al. 2007), em Carapa guianensis (Silva 2009), em mogno-africano (Albuquerque et al. 2013).

Entre os solutos envolvidos no processo de ajustamento osmótico, a prolina tem se destacado na literatura como sendo um soluto compatível que ocorre em plantas em resposta a estresses ambientais. A prolina se acumula em uma variedade de espécies de plantas em resposta a 
estresses como seca, salinidade, temperaturas extremas, radiação ultravioleta e metais pesados (Siripornadulsil et al. 2002). Esse acúmulo está correlacionado à tolerância ao estresse, sendo a concentração deste aminoácido, geralmente encontrada em níveis mais elevados nas plantas tolerantes que nas sensíveis (Ashraf \& Foolad 2007). Sua principal função na planta é agir como agente osmorregulador em diversas espécies vegetais, sendo utilizada como indicador da resposta a estresse hídrico (Giannakoula et al. 2008).

De acordo com Costa (2009), além do aumento expressivo de prolina em folhas de andiroba (Carapa guianensis Aubl.), essas plantas, expostas à restrição hídrica, apresentaram percentuais mais elevados de extravasamento de eletrólitos. Da mesma forma, Carvalho (2010), observou que, o extravasamento de eletrólitos aumentou com a diminuição da disponibilidade hídrica no cultivo de mamoeira. Corroborando com os resultados encontrados neste trabalho com as espécies $M$. lathyroides e V. luteola que apresentaram diferenças significativas entre os tratamentos a partir dos 11 e 18d-DH, respectivamente, tanto em folhas como em raízes (Fig. 3). Diferente dos resultados encontrados em folhas de $D$. incanum (Fig. $3 \mathrm{E}$ ), onde não foram observadas diferenças significativas entre os tratamentos, apesar de ter aumentado os níveis de extravasamento de eletrólitos nas raízes dessa espécie. No entanto, até o final do período experimental pode-se observar que as três espécies apresentaram resultados semelhantes às plantas controle, evidenciando a recuperação do sistema de membranas nos órgãos afetados pelo estresse.

O extravasamento de eletrólitos observado sob a maior deficiência hídrica pode ser atribuído a uma consequência da limitação da fotossíntese imposta pelo estresse hídrico intenso que resulta na ruptura da integridade de membrana, por exemplo, devido à produção de formas reativas de oxigênio, ROS. Estes compostos altamente reativos diminuem a atividade de enzimas, causam peroxidação de lipídios e afetam praticamente todos os componentes fotossintéticos (Torres Neto 2005).

Danos em membranas a nível foliar podem ser um dos primeiros sinais ao estresse (Bajji et al. 2002). Em folhas de milho da linhagem L13.1.2 o estresse hídrico induziu um aumento de $23 \%$ na concentração de MDA em relação ao controle (Viana 2002). Freire (2016), estudando o teor de MDA (malondialdeído), em craibeira (Tabebuia aurea), observou que o status hídrico na folha não foi afetado com a imposição ao déficit hídrico.

Esses resultados corroboram com os encontrados neste trabalho para a espécie $V$. luteola que apresentou diferenças significativas na parte aérea e raiz, onde o incremento de MDA ocorreu a partir dos 11d-DH (Figs. 4E e 4F), assim como em raízes de $M$. lathyroides (Fig. 4B) e $D$. incanum (Fig. 4D), onde também foi observado aumento nos teores de MDA. Nestas duas espécies, porém, não houve acréscimo nos níveis de MDA em folhas, quando comparados ao controle.

Em aroeira-do-sertão níveis elevados de peroxidação lipídica foram registrados sob deficiência hídrica, no entanto estes níveis foram revertidos logo após a reidratação (Queiroz et al. 2002), assim como verificado em Desmodium (Fig. 5D).

A concentração de MDA e $\mathrm{H}_{2} \mathrm{O}_{2}$ foi avaliada em folhas de tomate como um indicador de estresse oxidativo (Rodrigues et al. 2010). Em plantas de trigo também foi verificado o aumento na concentração de $\mathrm{H}_{2} \mathrm{O}_{2}$ e de MDA sob deficiência hídrica (Esfandiari et al. 2007). Nesse sentido, baixas concentrações de $\mathrm{H}_{2} \mathrm{O}_{2}$ e MDA foram associadas com a tolerância ao estresse hídrico em plantas de ervilha (Sairam \& Saxena 2000) e de trigo (Esfandiari et al. 2007). Verificou-se nesse experimento significativo aumento nos níveis de MDA nas raízes das três espécies estudadas, sob condições de estresse, sugerindo danos nas membranas celulares (Figs. 4B, 4D e 4F). Esses resultados podem estar diretamente relacionados com os observados na avaliação de extravasamento de eletrólitos no mesmo órgão (Figs. 3B, 3D e 3F) e com o aumento nos níveis de $\mathrm{H}_{2} \mathrm{O}_{2}$ nas raízes de $M$. lathyroides e $D$. incanum. Em $V$. incanum, no entanto, não foram evidenciadas alterações nos níveis de $\mathrm{H}_{2} \mathrm{O}_{2}$ em raízes ou folhas.

$\mathrm{O}_{2} \mathrm{O}_{2}$ desempenha um papel duplo em plantas: em baixas concentrações, atua como uma molécula envolvida na tolerância ao desencadear mecanismos de sinalização para a aclimatação a vários estresses bióticos e abióticos. $\mathrm{H}_{2} \mathrm{O}_{2}$ também é citado como um regulador chave em uma ampla variedade de processos fisiológicos, tais como a senescência, fotorrespiração, fotossíntese, movimento dos estômatos, ciclo celular, no crescimento e desenvolvimento (Gill \& Tuteja 2010).

De acordo com que foi observado, plantas de $V$. luteola, não apresentaram alterações nos níveis de $\mathrm{H}_{2} \mathrm{O}_{2}$ durante o período experimental. No entanto, foi evidenciado que, nesta espécie, houve um acúmulo de prolina desde o primeiro período avaliado mantendo-se mesmo após a reidratação, o que pode ter contribuído para reduzir danos oxidativos.

A prolina tem sido considerada uma molécula com potencial antioxidante e potente inibidor da morte celular programada. Osmólitos como sorbitol, manitol e prolina tem sido testado na eliminação de radicais $\mathrm{OH}^{-}$. Portanto, prolina não é apenas uma molécula importante na sinalização redox, mas também um eficaz supressor de espécies reativas de oxigênio (EROs) produzidos em plantas sob condições de estresses como salinidade e desidratação (Smirnoff \& Cumbes 1989).

Baseando-se nos resultados obtidos nesse trabalho é possível afirmar que todas as espécies estudadas, mostraram alterações metabólicas expressivas em tecidos foliares e/ ou radiculares, como forma de adaptação à condição de restrição hídrica imposta durante o período avaliado. No entanto, $V$. luteola foi a única espécie que não apresentou alterações nos níveis de $\mathrm{H}_{2} \mathrm{O}_{2}$ em nenhum dos órgãos avaliados. Esses resultados podem evidenciar que o aumento de $\mathrm{H}_{2} \mathrm{O}_{2}$ nas demais espécies pode estar associado a um processo de sinalização através dessa molécula, o qual contribui na ativação de outros mecanismos, além dos avaliados nesta pesquisa, que pode ter contribuído para o 
restabelecimento das membranas evitando, desta forma, maiores percentuais de extravasamento de eletrólitos em $M$. lathyroides e $D$. incanum, quando comparados aos observados em $V$. luteola, nos mesmos períodos.

Pode-se inferir que as espécies estudadas são capazes de tolerar a restrição hídrica, na condição experimental utilizada, constituindo o acúmulo de osmólitos, como açúcares solúveis e prolina em raízes e folhas, uma resposta adaptativa comum, que contribui para redução do estresse oxidativo. O período de resposta e a diferença na concentração destes solutos durante o período de estresse imposto e de recuperação, sugerem mecanismos diferenciados ao déficit de água no solo, o que influi nas variações do conteúdo de peróxido de hidrogênio, teores de malondialdeído e do extravasamento de eletrólitos durante o período de estresse e de recuperação entre as espécies de leguminosas.

\section{REFERÊNCIAS}

Albuquerque, M.P.F., Moraes, F.K.C., Santos, R.I.N., Castro, G.L.S., Ramos, E.M.L.S. \& Pinheiro, H.A. 2013. Ecofisiologia de plantas jovens de mognoafricano submetidas à déficit hídrico e reidratação. Pesquisa agropecuária brasileira 48(1):9-16.

Ashraf, M. \& Foolad, M.R. 2007. Roles of glycine betaine and proline in improving plant abiotic stress resistance. Environmental and Experimental Botany 59(2):6-216.

Bajji, M., Kinet, J.M. \& Lutts, S. 2002. The use of the electrolyte leakage method for assessing cell membrane stability as a water stress tolerance test in durum wheat. Plant Growth Regulation 36(1):61-70.

Bezerra Neto, E. \& Barreto, L.P. 2011. Análises Químicas e Bioquímicas em Plantas. Editora da Universidade Federal Rural de Pernambuco, Recife. 267 p.

Bieleski, R.L. \& Turner, N.A. 1966. Separation and estimation of amino acids in crude plant extracts by thin-layer electrophoresis and chromatography. Analytical Biochemistry 17:278- 293.

Bürling, K., Cerovic, Z.G., Cornic, G., Ducruet, J.M., Noga, G. \& Hunsche, M. 2013. Fluorescence-

based sensing of drought-induced stress in the vegetative phase of four contrasting wheat genotypes. Environmental and Experimental Botany 89:51-59.

Cakmak, I. \& Horst, W.J. 1991. Effect of aluminium on lipid peroxidation, superoxide-dismutase, catalase, and peroxidase activities in root tips of soybean (Glycine max). Physiologia Plantarum 83:463-468.

Carvalho, M. 2010. Variações morfológicas e eficiência do uso da água em Ricinus communis L. submetida ao déficit hídrico regulado. Ilhéus - BA. Dissertação 95 f., Universidade Estadual de Santa Catarina, Florianópolis.

Chaves-Filho J.T. \& Stacciarini-Seraphin, E. 2001. Potencial osmótico e teor de carboidratos em Solanum lycocarpum. Revista Brasileira de Botânica 24(2):199-204.

Costa, M.A. 2009. Ocorrência de danos celulares e capacidade de defesa antioxidante em mudas de andiroba (Carapa guianensis Aubl.) sob duas condições de déficit hídrico e após reidratação. Dissertação 36 f., Universidade Federal Rural da Amazônia, Belém.

Driver, S.M. \& Kromdijk J. 2013. Will C3 crops enhanced with the C4 $\mathrm{CO} 2$ - concentrating mechanism live up to their full potential (yield)? Journal of Experimental Botany 64(13):3925-3935.

Esfandiari, E.O., Shakiba, M.R., Mahboob, S.A., Alyari, H. \& Toorchi, M. 2007. Water stress, antioxidant enzyme activity and lipid peroxidation in wheat seedling. Journal Food Agricultural Environment 5(1):149-153.

Freire, F.C.J., 2016. Características fisiológicas de mudas de Craibeira sob condições de deficiência hídrica. Alagoas. Dissertação 64f., Universidade Federal de Alagoas.

Giannakoula, A., Moustakas, M., Mylona, P., Papadakis, L. \& Yupsanis, T. 2008. Aluminum tolerance in maize is correlated with increased levels of mineral nutrients, carbohydrates and proline, and decreased levels of lipid peroxidation and Al accumulation. Journal of Plant Physiology 165:385-396.

Gill, S.S. \& Tuteja, N. 2010. Reactive oxygen species and antioxidant machinery in abiotic stress tolerance in crop plants. Plant Physiology and Biochemistry 48(12):909-930.

Graham, D. \& Smydzuc, J. 1965. Use of anthrone in the quantitative determination of hexose phosphates. Analytical Biochemistry 11:246-255.

Hamidou, F., Zombre, G., Doiuf, O., Diop, N.N., Guinko, S. \& Braconnier, S. 2007.Physiological, biochemical and agromorphological responses of fi ve cowpea genotypes (Vigna unguiculata (L.) Walp.) to water defi cit under glasshouse conditions. Biotechnologie, Agronomie, Société et Environnement 11:225-234.

Hoagland, D.R. \& Arnon, D.I. 1938. The water-culture method for growing plants without soil. California Agricultural Experimental Station. Circular n. 347.

Jaleel, C.A., Manivannan, P., Wahid, A., Farooq, M., Al-juburi, H.J., Somasundaram, R. \& Panneerselvam, R. 2009. Drought Stress in Plants: A Review on Morphological Characteristics and Pigments Composition. International Journal Agricultural Biology 11:100-105.

Machado, A. A \& Concenição, A. R. 2007. WinStat- Sistemas de análises estatísticas para Windows. Versão 2.11. Universidade Federal de Pelotas, Pelotas.

Maia, P.S.P., Neto, C.F.O, Castro, D.S., Freitas, J.M.N., Lobato, A.K.S. \& Costa, R.C.L. 2007. Conteúdo Relativo de Água, Teor de Prolina e Carboidratos Solúveis Totais em Folhas de Duas Cultivares de Milho submetidas a Estresse Hídrico. Revista Brasileira de Biociências 5(2):918-920.

Marur, C.J. 1998. Fotossíntese e translocação de carboidratos em algodoeiros submetidos a déficit hídrico após a aplicação de cloreto de mepiquat. Revista Brasileira de Fisiologia Vegetal 10(1):59-64.

Meneses, C.H.S.G., Lima, L.H.G., Lima, M.M.A. \& Vidal, M.S. 2006. Aspectos genéticos e moleculares de plantas submetidas ao déficit hídrico. Revista Brasileira de Oleaginosas e Fibrosas 10(1/2):10391072.

Mishra, B.K., Iannacone, R.., Petrozzab, A., Mishra, A., Armentano, N., Vecchia, G.L., Trtílekd, M., Cellini, F. \& Nedbal, L. 2012. Engineered drought tolerance in tomato plants is reflected in chlorophyll fluorescence emission. Plant Science 182:79-86.

Nepomuceno, A.L., Neumaier, N., Farias, J.R.B. \& Oya, T. 2001. Tolerância à seca em plantas: mecanismos fisiológicos e moleculares. Biotecnologia Ciência e Desenvolvimento 23:1218.

Nogueira, R.J.M.C., Albuquerque, M.B. \& Silva, E.C. 2005. Aspectos ecofisiológicos da tolerância à seca em plantas da caatinga. In Estresses ambientais: danos e benefícios em plantas. Universidade Federal Rural de Pernambuco, Recife, p. 22-31.

Oliveira-Neto, C.F., Lobato, A.K.S. \& Costa, R.C.L. 2006. Teor de carboidratos solúveis totais em folhas de duas cultivares de feijãocaupi sob estresse hídrico. Tecnologias para o agronegócio In Anais do I Congresso Nacional de Feijão-Caupi, Teresina, Embrapa MeioNorte, v. 1. CD-ROM.

Pagter, M., Bragato, G. \& Brix, H. 2005. Tolerance and physiological responses of Phragmites australis to water deficit. Aquatic Botany $81: 285299$.

Queiroz, C.G.S., Garcia, Q.S. \& Filho, J.P.L. 2002. Atividade fotossintética e peroxidação de lipídiosde membrana em plantas de aroeira-dosertão sob estresse hídrico e após reidratação. Brazilian Journal Plant Physiologiae. 14(1):59-63.

Rodriguez, E. S, Wilhelmi M. M. R, Luis M, Cervilla, B. B., Juan J. R, Rosales, M. A, Romero, L \& Ruiz J. M. 2010. Genotypic differences in some physiological parameters symptomatic for oxidative stress under moderate drought in tomato plants. Plant Science 178(1):30-40.

Saint Pierre, C., Crossa, J.L., Bonnett, D., Yamaguchi-Shinozaki, K. \& Reynolds, M. 2012. Phenotyping transgenic wheat for drought resistance. Journal Experimental Botany 63:1799-1808.

Santos, C.F., Lima, G.P.P. \& Morgado, L.B. 2010. Tolerância e caracterização bioquímica em feijão-caupi submetido a estresse hídrico na pré-floração. Naturalia 33:34-44.

Sairam R. \& Saxena D. 2000. Oxidative stress and antioxidants in wheat genotypes: possible mechanism of water stress tolerance. Journal of Agronomy and Crop Science 184:55-61. 
Silva, J.R.R. 2009. Comportamento ecofisiológico de plantas jovens de andiroba (Carapa guianensis Aubl.) sob dois regimes hídricos. Dissertação 40f., Universidade Federal Rural da Amazônia, Belém. Smirnoff, N. \& Cumbes, Q.J. 1989. Hydroxyl radical scavenging activity of compatible solutes. Phytochemistry 28:1057-1060.

Siripornadulsil, S, Traina, S. \& Sayre. R.T. 2002. Molecular mechanisms of proline-mediated tolerance to toxic heavy metals in transgenic microalgae. Plant Cell 14:2837-2847.

Souza, R.P., Machado, E.C., Silva, J.A.B., Lagoa, A.M.M.A. \& Silveira. J.A.G. 2004. Photosynthetic gas exchange, chlorophyll fluorescence and some associated metabolic changes in cowpea (Vigna unguiculata) during water stress and recovery. Environmental and Experimental Botany 51:p.45-56.
Torres Neto, A. 2005. Atributos fisiológicos e relações hídricas em genótipos de mamoeiro (Carica papaya L.) na fase juvenil. Tese 16f., Universidade Estadual do Norte Fluminense Darcy Ribeiro, Campos dos Goytacazes.

Velikova, V., Yordanov, I. \& Edreva, A. 2000. Oxidative stress and some antioxidant systems in acid rain-treated bean plants. Plant Science 151(1):59-66.

Viana, M.C.M. 2002. Déficit hídrico em genótipos de milho com tolerância diferencial à seca. Dissertação 75 p. Universidade Federal de Minas Gerais, Belo Horizonte.

Weidlich, E.W.A. \& Pescador, R.U. 2010. Alocação de recursos (carboidratos) no desenvolvimento inicial de plântulas de Schizolobium parahyba (Vell.) S.F. Blake (Fabaceae - Caesalpinioideae). Revista Árvore 34(4): 907-914. 